\title{
Erratum to: Abstract commensurability and quasi-isometry classification of hyperbolic surface group amalgams
}

\author{
Emily Stark ${ }^{1}$ (D)
}

Published online: 30 March 2017

(C) Springer Science+Business Media Dordrecht 2017

\section{Erratum to: Geom Dedicata (2017) 186:39-74 DOI 10.1007/s10711-016-0179-8}

In the bibliography item 17 , the name of the author is given incorrectly: It should be "Kapovich, M." rather than "Michael, K.".

The full name of the author is Michael Kapovich, where Michael is the first name and Kapovich is the family name.

The online version of the original article can be found under doi:10.1007/s10711-016-0179-8.

Emily Stark

emilyrstark@gmail.com

1 Department of Mathematics, University of Haifa, 199 Abba Khoushy Avenue, Mount Carmel, 3498838 Haifa, Israel 